\title{
Departamento de Enfermagem em Saúde Coletiva: duas décadas de feitos e compromissos com a enfermagem e a saúde da população
}

\author{
Elizabeth Fujimori', Renata FerreiraTakahashi², \\ Rosa Maria Godoy Serpa da Fonseca ${ }^{3}$
}

Nascido em 13 de fevereiro de 1987, 20 anos depois, o Departamento de Enfermagem em Saúde Coletiva da Escola de Enfermagem da Universidade de São Paulo pode dizer que tem cumprido à risca a missão de produzir e difundir conhecimentos, desenvolver o ensino e prestar serviços à comunidade, com vistas a formar profissionais competentes para atuar na assistência, no ensino e na pesquisa em saúde e em enfermagem, por meio do desenvolvimento de projetos inovadores e concordes com os princípios e fundamentos do Sistema Único de Saúde.

Pioneiro no país na esfera da Enfermagem em Saúde Coletiva, com projeção nacional e internacional, vem sendo referência para a formação de profissionais e pesquisadores. Prova disso é que grande parte de nossos egressos ocupam cargos de relevância em instituições públicas de saúde e de ensino. As parcerias com organizações científicas nacionais e internacionais revelam o nosso compromisso social com a inter-subjetividade e a inovação da ciência para que seja, ao mesmo tempo, atual, crítica e transformadora.

Para tanto, na pesquisa, tem buscado desenvolver metodologias visando à construção de um paradigma que tome como objeto o processo saúde-doença em sua dimensão coletiva e, conseqüentemente, seja capaz de transformar as práticas assistenciais para responder às especificidades dos perfis epidemiológicos da população. Assim, foi pioneiro na utilização das categorias sociais básicas da saúde coletiva como classe social, gênero e geração, além de outras de relevante importância para a construção desse novo conhecimento como vulnerabilidade, adesão à assistência à saúde, necessidades e competências profissionais, dentre outras. Ainda, do ponto de vista da inovação, tem desenvolvido estudos baseados na única teoria autóctone de enfermagem existente, qual seja a Teoria da Intervenção Práxica da Enfermagem em Saúde Coletiva, uma base fértil e promissora para a compreensão das necessidades de saúde da população e a conseqüente intervenção de enfermagem no processo saúde-doença dos diferentes grupos sociais. Com este mesmo intuito contribuiu também enormemente para o desenvolvimento do projeto desenvolvido pela Associação Brasileira de Enfermagem, a Classificação Internacional das Práticas de Enfermagem em Saúde Coletiva (CIPESC), de reconhecimento nacional e internacional como uma classificação específica de enfermagem embasada nos princípios norteadores da Reforma Sanitária no país e, portanto, do Sistema Único de Saúde.

Tanto quanto as metodologias, os temas que têm sido privilegiados são os que buscam dar luz aos problemas mais relevantes da saúde da nossa população como doenças sexualmente transmissíveis e aids, tuberculose, hanseníase, doenças prevalentes na infância, violência, drogas, entre outros.

Os frutos, as parcerias e os avanços conseguidos mostram que boa parte do compromisso do Departamento de Enfermagem em Saúde Coletiva está consolidada. Seu desafio atual é desenvolver competências para a educação, pesquisa e intervenção na perspectiva critico-emancipatória, seguindo adiante com os princípios que o constituíram há duas décadas e visando a um fazer comprometido, responsável, articulado e, ao mesmo tempo, revelador de que é possível a concepção e a implementação de políticas de saúde efetivamente transformadoras dos níveis e das condições de saúde da população como concebido pelo Sistema Único de Saúde.

Para comemorar essa trajetória e firmar o compromisso com esse futuro, o Departamento promoveu o I Simpósio Internacional de Políticas e Práticas em Saúde Coletiva na Perspectiva da Enfermagem, que teve como temas centrais Formação e Qualificação de Trabalhadores em Saúde Coletiva e Políticas e Práticas em Saúde Coletiva. Os artigos que compõem este número especial correspondem às falas dos palestrantes e às produções científicas premiadas no referido evento.

Ficam aqui nossos agradecimentos a todos os que de alguma forma têm participado da nossa trajetória, seja pelo reconhecimento do esforço empreendido, seja pelos desafios que nos têm colocado e que sempre tentamos e vamos continuar tentando superar.

\footnotetext{
${ }^{1}$ Professor Associado do Departamento de Enfermagem em Saúde Coletiva da Escola de Enfermagem, Universidade de São Paulo. Líder do Grupo de Pesquisa Aspectos Nutricionais do Processo Saúde e Doença. Presidente da Comissão de Pesquisa da Escola de Enfermagem, Universidade de São Paulo (EEUSP). São Paulo, SP, Brasil. efujimor@usp.br ${ }^{2}$ Livre-Docente do Departamento de Enfermagem em Saúde Coletiva da Escola de Enfermagem, Universidade de São Paulo (EEUSP). São Paulo, SP, Brasil. rftakaha@usp.br ${ }^{3}$ Professora Titular do Departamento de Enfermagem em Saúde Coletiva da Escola de Enfermagem, Universidade de São Paulo (EEUSP). São Paulo, SP, Brasil. rmgsfon@usp.br
} 